\title{
Untargeted metabolic profiling reveals distinct patterns of thermal sensitivity in two related notothenioids
}

\author{
Anja Rebelein ${ }^{\mathrm{a}}$, Hans-Otto Pörtner ${ }^{\mathrm{a}, \mathrm{b}}$, Christian Bock ${ }^{\mathrm{a}, \text { * }}$ \\ ${ }^{\text {a }}$ Alfred-Wegener-Institute Helmholtz-Centre for Polar and Marine Research, Integrative Ecophysiology, Am Handelshafen 12, 27570 Bremerhaven, Germany \\ ${ }^{\mathrm{b}}$ University of Bremen, 28359 Bremen, Germany
}

\section{A R T ICLE IN F O}

\section{Keywords:}

${ }^{1} \mathrm{H}-\mathrm{NMR}$ spectroscopy

Antarctic fish

HR-MAS

metabolomics

multivariate statistics

\begin{abstract}
A B S T R A C T
Antarctic marine ectothermal animals may be affected more than temperate species by rising temperatures due to ongoing climate change. Their specialisation on stable cold temperatures makes them vulnerable to even small degrees of warming. Thus, addressing the impacts of warming on Antarctic organisms and identifying their potentially limited capacities to respond is of interest.

The objective of the study was to determine changes in metabolite profiles related to temperature acclimation. In a long-term experiment adult fish of two Antarctic sister species Notothenia rossii and Notothenia coriiceps were acclimated to $0{ }^{\circ} \mathrm{C}$ and $5{ }^{\circ} \mathrm{C}$ for three months. Impacts and indicators of acclimation at the cellular level were determined from metabolite profiles quantified in gill tissue extracts using nuclear magnetic resonance (NMR) spectroscopy. Furthermore, the metabolite profiles of the two con-generic species were compared.

NMR spectroscopy identified 37 metabolites that were present in each sample, but varied in their absolute concentration between species and between treatments. A decrease in amino acid levels indicated an increased amino acid catabolism after incubation to $5{ }^{\circ} \mathrm{C}$. In addition, long term warming initiated shifts in organic osmolyte concentrations and modified membrane structure observed by altered levels of phospholipid compounds. Differences in the metabolite profile between the two notothenioid species can be related to their divergent lifestyles, especially their different rates of motor activity. Increased levels of the Krebs cycle intermediate succinate and a higher reduction of amino acid concentrations in warm-acclimated $N$. rossii showed that $N$. rossii is more affected by warming than $N$. coriiceps.
\end{abstract}

\section{Introduction}

Climate change is expected to produce the most dramatic environmental changes in the polar regions. Turner et al. reported an increase of the average sea surface temperature up to $2.8{ }^{\circ} \mathrm{C} / \mathrm{y}$ around the Antarctic peninsula and its offshore islands for the period 1951-2000, presently followed by a cooling trend (Turner et al., 2005; Turner et al., 2016). According to the recent IPCC report water temperatures will reach temperatures above $5{ }^{\circ} \mathrm{C}$ around the Antarctic Peninsula by the end of this century (IPCC, 2014). Temperature affects the performance of organisms on all organisational levels, such as the kinetic energy of molecules, macromolecular stability, membrane properties, cellular processes and metabolic and physiological activities. In animals these changes result in an altered energy demand of cardiovascular, respira- tory, gastrointestinal and excretory systems and therefore contribute to shape whole-organism performance (Guderley, 2004).

Temperature also determines the geographical distribution of species and their role within ecosystems. With ongoing climate change and its reported effects on organism and ecosystems, studies revealing the impacts of increasing temperature become more and more timely (Pörtner and Peck, 2010).

Warming has specific effects on the Antarctic fauna, in particular, on ectothermic organisms like fishes. The recent literature provides a profound overview of warming induced organismal changes in Antarctic fishes (see review of e.g. Pörtner et al., 2007), mainly under acute temperature changes. An increase in temperature is accompanied by elevated energy demand, visible in increased oxygen consumption rates and circulatory performance of Antarctic fishes during acute warming (Mark et al., 2002; Bilyk and DeVries, 2011). Longer incubation for

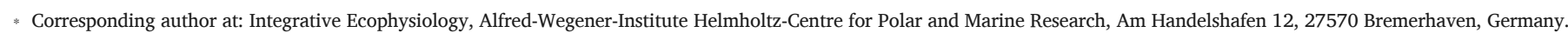
Email address: Christian.Bock@awi.de (C. Bock)
} 
9 weeks to $4{ }^{\circ} \mathrm{C}$ showed a complete compensation of metabolic costs at the organismal level in Trematomus bernacchii (Sandersfeld, 2015). At the molecular level Windisch et al. (2011) could show that respiratory chain capacities increased accompanied by a shift from lipid to carbohydrate catabolism in the liver of the Antarctic eelpout Pachycara brachycephalum after long term acclimation to $5{ }^{\circ} \mathrm{C}$. However, very little is known about the actual metabolic changes in Antarctic notothenioid fish after long term acclimation to warming. We therefore applied an untargeted NMR based metabolic profiling approach to gill tissue as an aerobic oxygen supplying organ, which sets whole organism performance. Recently, metabolomics was successfully applied to environmental studies on marine organisms (see reviews by Viant et al., 2003; Wu et al., 2008) and a couple of applications to marine fish can already be found in the present literature (e.g. Mannina et al., 2008; Liu et al., 2011; Picone et al., 2011). One of the main advantages using metabolic profiling is the integrative nature of this approach (Lenz and Wilson, 2007), as it provides an almost complete picture of the main concentration changes of metabolites under specific conditions. Thereby, the key metabolic responses to a specific stressor can be revealed (Dunn and Ellis, 2005).

In the present study, the thermal sensitivity and metabolic responses of two closely related Antarctic notothenioids were investigated after incubation for 3 months to $5{ }^{\circ} \mathrm{C}$. The chosen temperature relates to the temperature expected in Antarctic surface waters around King George Island in the year 2100. Gill tissue extracts of the Antarctic rock cod Nothothenia rossii and the Antarctic yellow rock cod Nothothenia coriiceps were taken and analysed using untargeted NMR-based metabolic profiling.

Windisch et al. (2014) suggested a shift of an amino-acid and lipid-based metabolism to carbohydrate catabolism in the liver of $P$. brachycephalum after long term warming. Kullgren et al. (2013) found lower amounts of amino acids after long-term acclimation in the plasma of Atlantic salmon. In addition, new proteins need to be synthesised to compensate for damaged and non-functional proteins at higher temperatures and Antarctic species seem to have difficulties to synthesize proteins to full function (Peck, 2016). Therefore, our main focus laid on amino acids, especially those used for energy provision and involved in protein synthesis. Gill tissue was chosen for our study, as it is a high metabolic tissue that does not exhibit big metabolite storage capacities, such as muscle and liver for lipids (Sheridan, 1988). The investigation of the metabolic profile of the notothenioids provides an outline for metabolic shifts, which can serve as basis for further analyses. Investigating polar extracts placed a major focus on possible changes in the amino acid metabolism, the energy metabolism and cellular membrane structure. Furthermore, the comparison of the two con-generic notothenioid species $N$. rossii and $N$. coriiceps could point out possible distinctions of their acclimation capacities, which might be related to their divergent ecological backgrounds.

\section{Materials and methods}

\subsection{Animal collection and acclimation experiment}

Notothenia rossii and Notothenia coriiceps were caught in Potter Cove of King George Island (coordinates $62^{\circ} 14^{\prime} \mathrm{S}, 058^{\circ} 41^{\prime} \mathrm{W}$ ) between February and March of 2010 using baited traps. The recorded water temperature during that time was $1.72 \pm 0.13{ }^{\circ} \mathrm{C}$ and the salinity $34.03 \pm 0.07$ PSU.

All animals were transported to the Alfred-Wegener-Institute (AWI) in Bremerhaven in an aquarium container on board of RV Polarstern during VII/3-4. Afterwards the animals were kept in circular tanks with a volume of $2.6 \mathrm{~m}^{3}$ under a $12 \mathrm{~h}$ light/12 $\mathrm{h}$ dark cycle in the polar aquarium facility of the institute until the experiment.
For the long-term acclimation experiment 5-7 individuals were placed in individual tanks for 3 months. For both species, N. rossii and $N$. coriiceps, fishes were randomly selected and kept each at temperatures of $0 \pm 0.2{ }^{\circ} \mathrm{C}$ (control group) and $5 \pm 0.2{ }^{\circ} \mathrm{C}$. The salinity was maintained at $\sim 32.5$ PSU. Water quality was controlled conducting weekly ammonium, nitrite and nitrate tests (Merck KGaA, Germany). During the experimental period, the notothenioids were fed with thawed common cockles (Cerastoderma edule) twice a week.

After the acclimation experiment the experimental fish were anaesthetised with $0.5 \mathrm{~g} / 1$ tricaine methano-sulfonate (MS222) and sacrificed by cutting the spinal cord. Gill tissues were dissected, flash frozen in liquid nitrogen and stored at $-80{ }^{\circ} \mathrm{C}$ until extraction.

The average standard length of the animals kept at $0{ }^{\circ} \mathrm{C}$ was $30 \pm 2 \mathrm{~cm}$ for $N$. rossii $(n=12)$ and $32 \pm 3 \mathrm{~cm}$ for $N$. coriiceps $(\mathrm{n}=12)$. The average weight was $411 \pm 75 \mathrm{~g}$ for $N$. rossii and $396 \pm 90 \mathrm{~g}$ for $N$. coriiceps. For the animals acclimated to $5{ }^{\circ} \mathrm{C}$ the average standard length was $31 \pm 4 \mathrm{~cm}$ at an average weight of $510 \pm 166 \mathrm{~g}$ for $N$. rossii ( $n=14$ ) and $31 \pm 2 \mathrm{~cm}$ at $560 \pm 80 \mathrm{~g}$ for $N$. coriiceps $(n=12)$.

\subsection{Sample preparation}

Metabolites of fish gill tissue were analysed using Nuclear Magnetic Resonance (NMR) spectroscopy. Polar metabolites were extracted from tissues according to the two-step extraction protocol developed by Wu et al. (2008). The pre-weighed $(\sim 100 \mathrm{mg})$ frozen gill tissue samples were added to homogenisation tubes containing $400 \mu$ ice-cold methanol and $125 \mu \mathrm{l}$ ice-cold Milli-Q water. For homogenisation samples were minced in a bead-based Precellys 24 (Bertin Technologies, France) for 1 cycle of $20 \mathrm{~s}$ at $6000 \mathrm{rpm}$ and temperatures between 0 and $4{ }^{\circ} \mathrm{C}$. The homogenisation step was done in groups of four samples to prevent tissue from thawing before homogenisation. $400 \mu \mathrm{l}$ chloroform and $400 \mu \mathrm{l}$ Milli-Q water were added to each homogenate before they were mixed thoroughly for $15 \mathrm{~s}$. All samples were left on ice for $10 \mathrm{~min}$ to partition and thereafter centrifuged at $3000 \mathrm{~g}$ at $4{ }^{\circ} \mathrm{C}$ for $10 \mathrm{~min}$. The upper, polar layer was transferred into a $2 \mathrm{ml}$ Eppendorf cup and dried in a rotational vacuum concentrator (RVC 2-18 HCl, Christ GmbH, Germany) at room temperature overnight.

\subsection{Untargeted NMR based metabolic profiling}

Dried polar gill extracts were re-suspended in deuterated water $\left(\mathrm{D}_{2} \mathrm{O}\right)$ to a final concentration of $1 \mathrm{~g}$ frozen gill tissue $/ \mathrm{ml}$ solvent. The $\mathrm{D}_{2} \mathrm{O}$ contained $0.05 \mathrm{wt} \%$ of 3-(trimethylsilyl) propionic-2,2,3,3- $\mathrm{d}_{4}$ acid, sodium salt (TSP) (Sigma Aldrich, St. Louis, USA). TSP was used as chemical shift and quantification standard. For each sample $50 \mu \mathrm{l}$ of the resuspended gill extracts were analysed.

The spectra were measured using an ultra-shielded vertical $9.4 \mathrm{~T}$ NMR spectrometer (Avance III HD 400 WB, Bruker-BioSpin GmbH, Germany) at a proton frequency of $400 \mathrm{MHz}$ in combination with TOPSPIN 3.2 software (TopSpin 3.2, Bruker-BioSpin GmbH, Germany) and a high-resolution magic angle triple tuneable ${ }^{1} \mathrm{H}_{-}{ }^{31} \mathrm{P}_{-}{ }^{13} \mathrm{C}$ probe (HRMAS). All samples were analysed using one dimensional ${ }^{1} \mathrm{H}-\mathrm{HRMAS}$ NMR spectroscopy with water presaturation at $21^{\circ} \mathrm{C}$. A set of four different NMR techniques were used for each sample as described in Schmidt et al. (2017). A. a standard one-pulse pulse sequence, B. a Call-Purcell-Meiboom-Gill (CPMG) sequence, C. a Nuclear Overhauser Effect Spectroscopy (NOESY) protocol and finally D. a J resolved (J-RES) sequence for signal assignment. The CPMG protocol was used for further analysis, measured with a relaxation delay of $4 \mathrm{~s}$, a sweep width of $8803 \mathrm{~Hz}$ and $70 \mathrm{k}$ data points. 32 scans were acquired for each spectrum. 
The spectra were processed and analysed with Chenomx NMR Suite 8.0 software (Chenomx Inc., Canada). Fourier-transformed spectra were multiplied with an exponential weighing function corresponding to a line-broadening between 0.5 and $1 \mathrm{~Hz}$ depending on spectrum quality. Before analysing them, all spectra were manually corrected for phase and baseline and referenced to TSP. The metabolite peaks of the processed spectra were analysed and assigned to their chemical shifts using the Chenomx database as a reference. The assigned peaks were compared and confirmed by chemical shift values in the literature (Fan, 1996; Gribbestad et al., 2005; Castejón et al., 2010). The concentration of the assigned metabolites was provided by the Chenomx software based on the concentration of the internal standard TSP. In addition to the one-dimensional ${ }^{1} \mathrm{H}-\mathrm{NMR}$ spectrometry, a two-dimensional heteronuclear single quantum coherence measurement $\left({ }^{1} \mathrm{H}_{-}{ }^{13} \mathrm{C}\right.$ HSQC NMR) of a $N$. rossii sample was taken and the resulting 2D spectrum was used to assist in assigning signals from the ${ }^{1} \mathrm{H}-\mathrm{NMR}$ spectra (see Supplementary S1). The correlated resonances were identified using the online database Spectral Database for Organic Compounds (SDBS, National Institute of Advanced Industrial Science and Technology, Japan) together with data from the literature (see above).

To gain further information about the presence of phosphorus-containing metabolites in the tissue extract, a ${ }^{31} \mathrm{P}$ spectrum was measured with a relaxation delay of $8 \mathrm{~s}$, a sweep width of $8012 \mathrm{~Hz}$ and $4 \mathrm{k}$ data points. The peaks of the spectrum were assigned to metabolites using reference spectra from the literature (Canioni and Quistorff, 1994; Bock et al., 2001).

\subsection{Statistical analysis}

Metabolite concentrations in the gill tissue extracts of the different groups were analysed using univariate and multivariate statistical analysis. All obtained metabolite concentrations were related to a metabolite with a constant concentration for normalisation (Craig et al., 2006). The normalisation was performed on the adenosine signal, as the total adenosine concentration is expected to be constant, especially for long-term acclimation, just the number of bound phosphate groups varies (Hochachka and McClelland, 1997). In addition, a generalised log-transformation was applied to the normalised metabolite concentrations to stabilise the variance across the detected metabolite concentrations (Purohit et al., 2004).

For multivariate analysis, unsupervised principle component analysis (PCA) and supervised partial least-squares discriminant analysis (PLS-DA) were applied using Metaboanalyst software (Metaboanalyst 3.0; Xia and Wishart, 2016). Multivariate analysis was conducted for each pair of groups separately (both control groups, control vs. $5{ }^{\circ} \mathrm{C}$ acclimated group for each species and both groups acclimated to the elevated temperature). Results are presented reporting the scores of the principle components and showing a 2D score plot of the first two principle components. An example for a PCA and a PLS-DA loadings plot is presented in the Supplementary (S2).

Univariate analysis including parametric Student's $t$-test and non-parametric Mann-Whitney test was performed with SigmaPlot (SigmaPlot 12.0, Systat Software Inc.) to detect and validate the changes in the metabolite concentrations between the pairs of grouped samples investigated by multivariate analysis. The threshold for significance was a $p$-value $<0.05$ for all tests.

\section{Results}

Fig. 1 presents an example of a typical ${ }^{1} \mathrm{H}-\mathrm{CPMG}-\mathrm{NMR}$ spectrum acquired from an aqueous gill tissue extract of Notothenia rossii obtained from this study. Signal changes of 41 signals were analysed from gill tissue. Four signals could not be assigned to a specific metabolite, lead- ing to an overall identification of 37 metabolites. The concentration changes were used to analyse for a potential species and temperature dependent metabolic response. In Table 1 all identified metabolites are listed according to their metabolite classes and to their characteristic chemical shifts (only relevant chemical shifts are specified for each metabolite).

All spectra were dominated by the organic osmolytes trimethylamine-N-oxide (TMAO) and taurine, showing large peaks in the spectrum area between 3.25 and $3.30 \mathrm{ppm}$ and $3.40-3.45 \mathrm{ppm}$. In general, osmolytes and amino acids represented the main metabolite groups detected in the aqueous extracts.

In the aliphatic region signals characterising the free amino acids leucine, isoleucine, valine, alanine, glutamine, glutamate and methionine were identified. The organic acids occurring in this region were lactate, succinate, citrate and acetate. A small singlet at $2.72 \mathrm{ppm}$ was identified as dimethylamine (DMA).

Overlapping signals in the hydroxylic region resulted from various alpha amino acids, alcohols, polyols and saccharides. Characteristic patterns could be assigned to metabolites such as choline, O-phosphocholine (PC) and sn-glycero-3-phosphocholine (GPC). Peaks at 3.04 ppm and $3.94 \mathrm{ppm}$ belonged to creatine and phosphocreatine. In addition, the distinct pattern of the polyol myo-inositol was detected. The amino acid glycine showed a recognisable singlet at $3.56 \mathrm{ppm}$ and the osmolyte betaine at $3.87 \mathrm{ppm}$. Identified sugars in the hydroxylic region were glucose and UDP-glucose.

Signals obtained in the aromatic region were attributed to the aromatic amino acids phenylalanine, tyrosine and histidine. Other assigned metabolites were the nucleoside inosine and nucleotide derivates, such as adenosinetriphosphate (ATP), adenosinediphosphate (ADP), nicotinamide adenine dinucleotide (NADH) and nicotineamide adenine dinucleotide phosphate (NADPH). The two peaks at $8.19 \mathrm{ppm}$ and $8.21 \mathrm{ppm}$ indicated the presence of the purine derivative hypoxanthine.

The composition of assigned metabolites in the tissue extracts did not differ between the two notothenioid species, except for varying compound concentrations. Univariate and multivariate statistical analyses were used to reveal differences in metabolite concentrations in both Antarctic notothenioid species. The principal component analysis (PCA) of all gill tissue extract samples at $0{ }^{\circ} \mathrm{C}$ displays a homogeneous group with no detected outliers. $96.4 \%$ of the total variance in the metabolite concentrations was explained by the first principle component (PC1, Fig. 2A).

In order to address potential differences in metabolite concentrations between both groups a supervised partial least square discriminant analysis (PLS-DA) was performed. In the supervised PLS-DA a sharpening of the separation between the groups found in the PCA is performed by rotating the PCA components to obtain a maximum separation among classes. Other than the PCA the PLS-DA does take into account the correlation of the dependent and the independent variables. Fig. 2B presents the resulting score plot of the PLS-DA showing a significant separation of data from the two Antarctic notothenioid species under control conditions.

Table 2 lists the detected significant differences in metabolite concentrations based on a Student's t-test or a Mann-Whitney Rank Sum test as indicated in the table. The largest difference was found in the concentration of the osmolyte TMAO. $N$. coriiceps had almost twice the concentration found in $N$. rossii.

As a general pattern indicated by significant differences in the metabolite concentrations of the gill extracts, $N$. coriiceps had lower amounts of the free amino acids methionine, phenylalanine and tyrosine. All metabolites listed in the group of energy supplying compounds, such as creatine, phosphocreatine, citrate, glucose and NADH/ NADPH did also exist in lower concentrations in this benthic species in comparison to $N$. rossii. Furthermore, metabolites involved in 
A
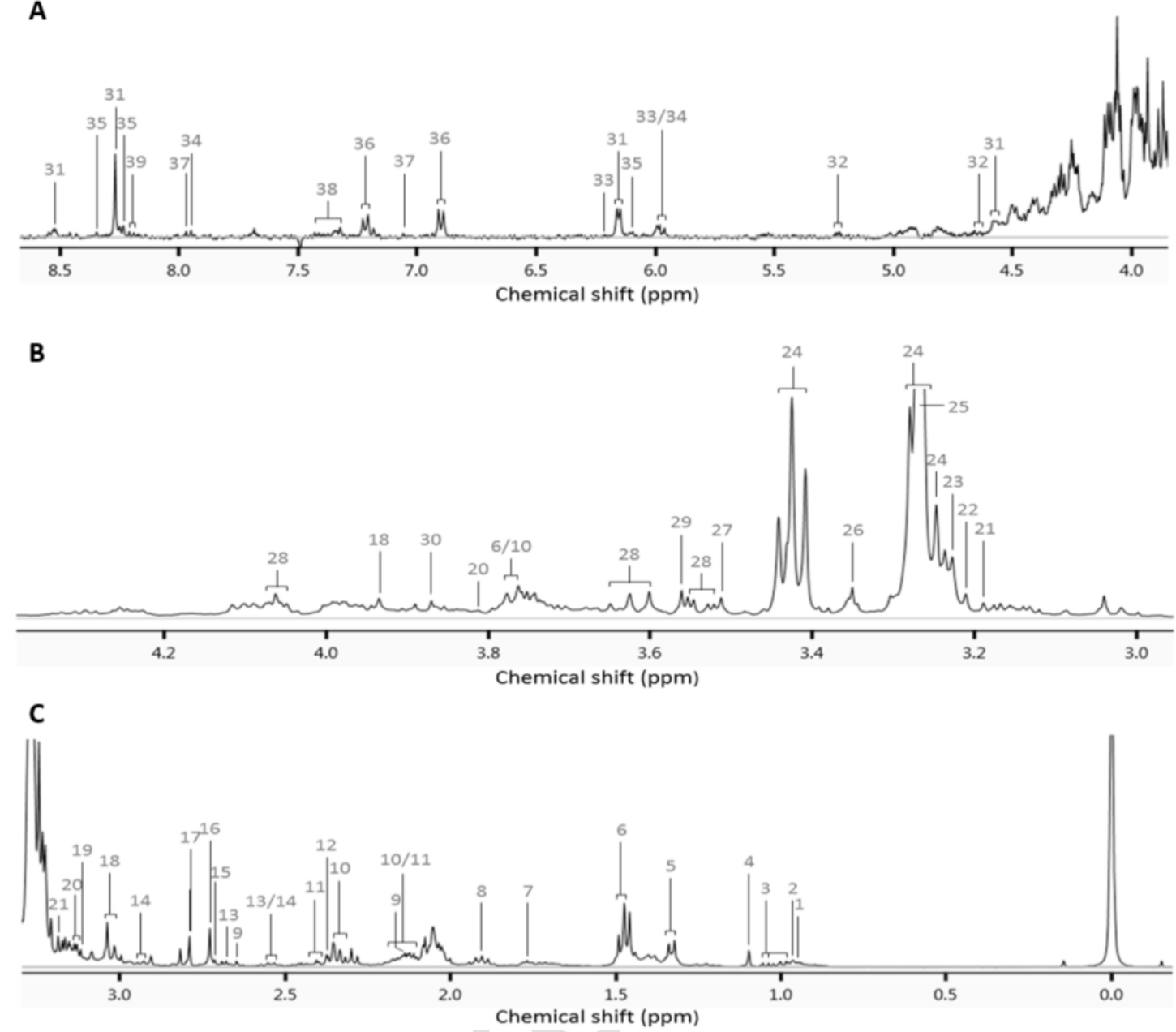

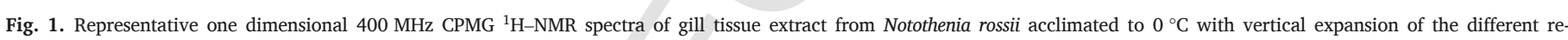

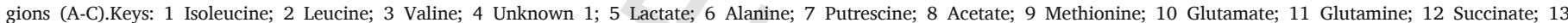

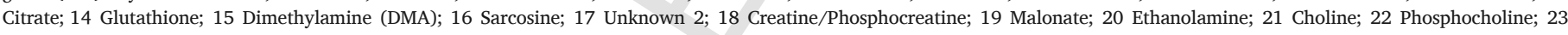

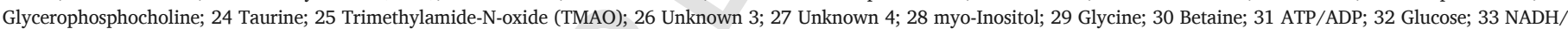

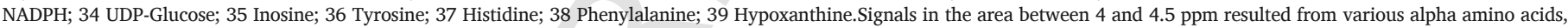
alcohols, polyols and saccharides.

phospholipid metabolism, such as choline and its derivative glycerophosphocholine, were present in higher concentrations in the pelagic swimmer $N$. rossii than in its sister species.

No general pattern could be observed for metabolites belonging to various metabolic groups or having an unknown function (listed as miscellaneous). The amount of the purine derivative inosine was higher in $N$. coriiceps, while acetate and sarcosine levels were lower.

\subsection{Differences in metabolite concentrations after warm-acclimation}

In general, no additional metabolites were found in the gill samples taken from fish after long-term acclimation to $5{ }^{\circ} \mathrm{C}$ compared to the control group. Nevertheless, metabolite concentrations varied in the metabolic profiles between the groups for both notothenioids.

As in the PCA analysis of the control groups, there were no outliers detected in the different groups (data not shown). For the $N$. rossii groups PC1 explains $95.9 \%$ of the variance and the PCA analysis for $N$. coriiceps provided evidence, that $97.3 \%$ of the variance can be explained by the first principle component, demonstrating again a decent homogeneity of the analysed groups.

Fig. 3 displays the supervised PLS-DA between gill tissue samples of the two notothenioids under control and $5{ }^{\circ} \mathrm{C}$. The PLS-DA was per- formed for each species separately as was the PCA analysis. The score plots of the PLS-DA depict a clear separation for both, N. rossii and $N$. coriiceps (Fig. 3). The ellipses corresponding to the confidence interval of $95 \%$ were clearly separated from control and the $5{ }^{\circ} \mathrm{C}$ acclimated group.

Table 3 summarises the significant changes in metabolite concentrations during thermal acclimation for each notothenioid species.

The main metabolite groups affected were amino acids, osmolytes and phospholipid metabolism related compounds. The largest changes are visible in the concentration of the osmolyte TMAO and the structural component myo-inositol, which both exist in high concentrations in the tissue, and of acetate (data not shown, see Supplementary material S3).

Osmolyte concentrations in gill tissues decreased after $5{ }^{\circ} \mathrm{C}$ incubation, a trend seen for all osmolytes. Significant changes were confirmed for TMAO and betaine in $N$. rossii and for TMAO and DMA in N. coriiceps. In addition, the concentration of the amino acid glycine was significantly decreased (see Table 3).

The concentrations of choline, GPC and myo-inositol, which are related to phospholipid metabolism, were significantly lower in the $5{ }^{\circ} \mathrm{C}$ acclimated groups than in the control group in N. rossii. The same was observed for choline and myo-inositol in $N$. coriiceps. 
Table 1

List of compounds identified in the ${ }^{1} \mathrm{H}-\mathrm{NMR}$ spectrum of the gill tissue extract of Notothenia rossii and Notothenia coriiceps and corresponding chemical shifts. (Multiplicity s: singlet, d: doublet, t: triplet, m: multiplet).

\begin{tabular}{|c|c|}
\hline Metabolite & Chemical shift \\
\hline \multicolumn{2}{|l|}{ Amino acids } \\
\hline Alanine & $1.48(\mathrm{~d}), 3.78(\mathrm{~m})$ \\
\hline Glutamate & $2.05(\mathrm{~m}), 2.13(\mathrm{~m}), 2.35(\mathrm{~m}), 3.76(\mathrm{~m})$ \\
\hline Glutamine & $2.12(\mathrm{~m}), 2.15(\mathrm{~m}), 2.43(\mathrm{~m}), 2.46(\mathrm{~m})$ \\
\hline Glycine & $3.56(s)$ \\
\hline Histidine & $7.06(\mathrm{~s}), 7.97(\mathrm{~s})$ \\
\hline Isoleucine & $0.94(t), 0.99(d)$ \\
\hline Leucine & $0.95(d), 0.97(d)$ \\
\hline Methionine & $2.14(\mathrm{~s})$ \\
\hline Phenylalanine & $7.33(\mathrm{~m}), 7.36(\mathrm{~m}), 7.43(\mathrm{~m})$ \\
\hline Tyrosine & $6.90(d), 7.22(d)$ \\
\hline Valine & $0.97(d), 1.05(d)$ \\
\hline \multicolumn{2}{|l|}{ Organic osmolytes } \\
\hline Betaine & $3.87(s)$ \\
\hline Dimethylamine & $2.72(s)$ \\
\hline Taurine & $3.26(\mathrm{t}), 3.43(\mathrm{t})$ \\
\hline Trimethylamine $\mathrm{N}$-oxide & $3.27(\mathrm{~s})$ \\
\hline \multicolumn{2}{|l|}{ Energy metabolism } \\
\hline $\mathrm{ADP} / \mathrm{ATP}$ & $4.58(\mathrm{~m}), 6.15(\mathrm{~d}), 8.27(\mathrm{~s}), 8.52(\mathrm{~s})$ \\
\hline Creatine/- phosphate & $3.04(\mathrm{~s}), 3.94(\mathrm{~s})$ \\
\hline Glucose & $4.65(d), 5.24(d)$ \\
\hline Lactate & $1.33(\mathrm{~d})$ \\
\hline NADH/NADPH & $5.98(\mathrm{~d}), 6.21(\mathrm{~d}), 8.23(\mathrm{~s}), 8.46(\mathrm{~s})$ \\
\hline UDP-glucose & $5.98(d), 5.99(d), 7.94(d)$ \\
\hline \multicolumn{2}{|l|}{ Krebs cycle intermediates } \\
\hline Citrate & $2.54(\mathrm{~d}), 2.70(\mathrm{~d})$ \\
\hline Succinate & $2.41(\mathrm{~s})$ \\
\hline \multicolumn{2}{|l|}{ Phospholipid related compounds } \\
\hline Choline & $3.19(\mathrm{~s})$ \\
\hline Ethanolamine & $3.13(\mathrm{~m}), 3.81(\mathrm{~m})$ \\
\hline myo-Inositol & $3.54(\mathrm{~m}), 3.63(\mathrm{~m}), 4.06(\mathrm{~m})$ \\
\hline O-Phosphocholine & $3.21(\mathrm{~s})$ \\
\hline sn-Glycero-3-phosphocholine & $3.23(\mathrm{~s})$ \\
\hline \multicolumn{2}{|l|}{ Miscellaneous } \\
\hline Acetate & $1.91(\mathrm{~s})$ \\
\hline Anserine & $3.78(\mathrm{~s})$ \\
\hline Dimethyl sulfone & $3.16(\mathrm{~s})$ \\
\hline Glutathione & $2.52(\mathrm{~m}), 2.56(\mathrm{~m}), 2.99(\mathrm{~m})$ \\
\hline Hypoxanthine & $8.19(\mathrm{~d}), 8.21(\mathrm{~d})$ \\
\hline Inosine & $6.09(\mathrm{~d}), 8.24(\mathrm{~s}), 8.35(\mathrm{~s})$ \\
\hline Malonate & $3.12(\mathrm{~s})$ \\
\hline Putrescine & $1.77(\mathrm{~m}), 3.05(\mathrm{~m})$ \\
\hline Sarcosine & $2.73(\mathrm{~s})$ \\
\hline
\end{tabular}

The acetate concentration was significantly reduced in warm-acclimated samples, while inosine content was elevated in both notothenioids. However, the total inosine concentration (mean concentrations of $0.031 \mu \mathrm{mol} / \mathrm{g}$ fresh weight in $N$. rossii and $0.059 \mu \mathrm{mol} / \mathrm{g}$ fresh weight in $N$. coriiceps under control conditions) was very low in gill tissue extracts compared to most other detected metabolites (e.g. Glucose: $0.198 \mu \mathrm{mol} / \mathrm{g}$ fresh weight in $N$. rossii and $0.143 \mu \mathrm{mol} / \mathrm{g}$ fresh weight in $N$. coriiceps, respectively).

While several metabolite concentrations in gill tissue extracts of $N$. rossii and $N$. coriiceps showed the same trends during warm-acclimation, some differences in the response to elevated temperatures were detected.

Supervised PLS-DA analysis provided evidence for a possible functional differentiation of both notothenioid species acclimated to $5{ }^{\circ} \mathrm{C}$. Fig. 4 illustrates this segregation marked by the ellipses representing the $95 \%$ confidence interval.
A

\section{Control groups}

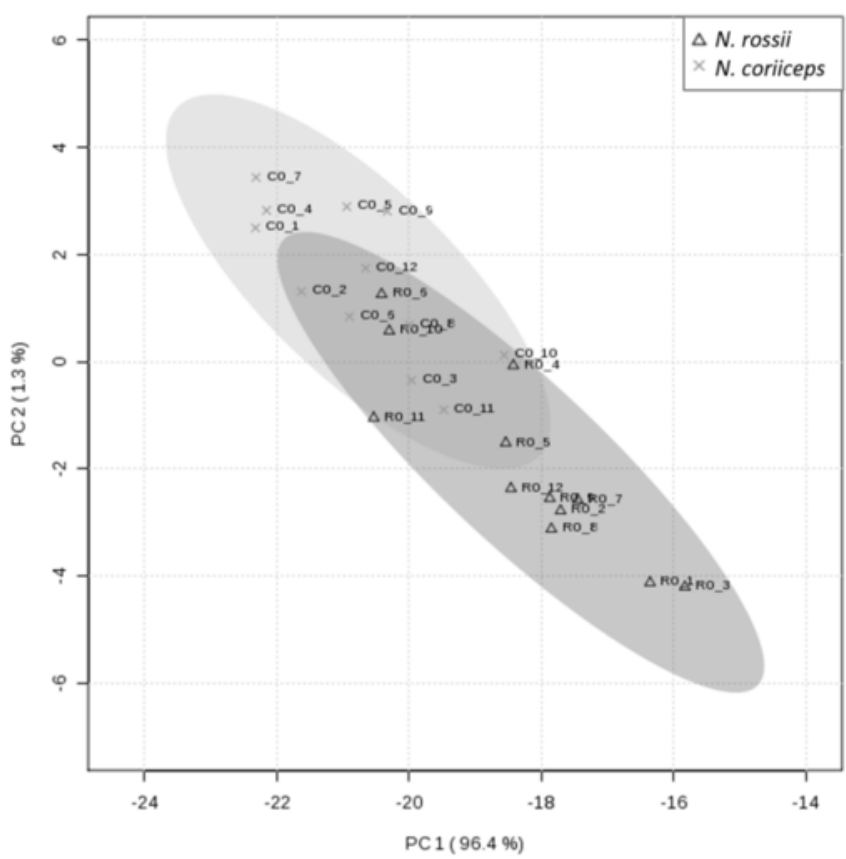

B

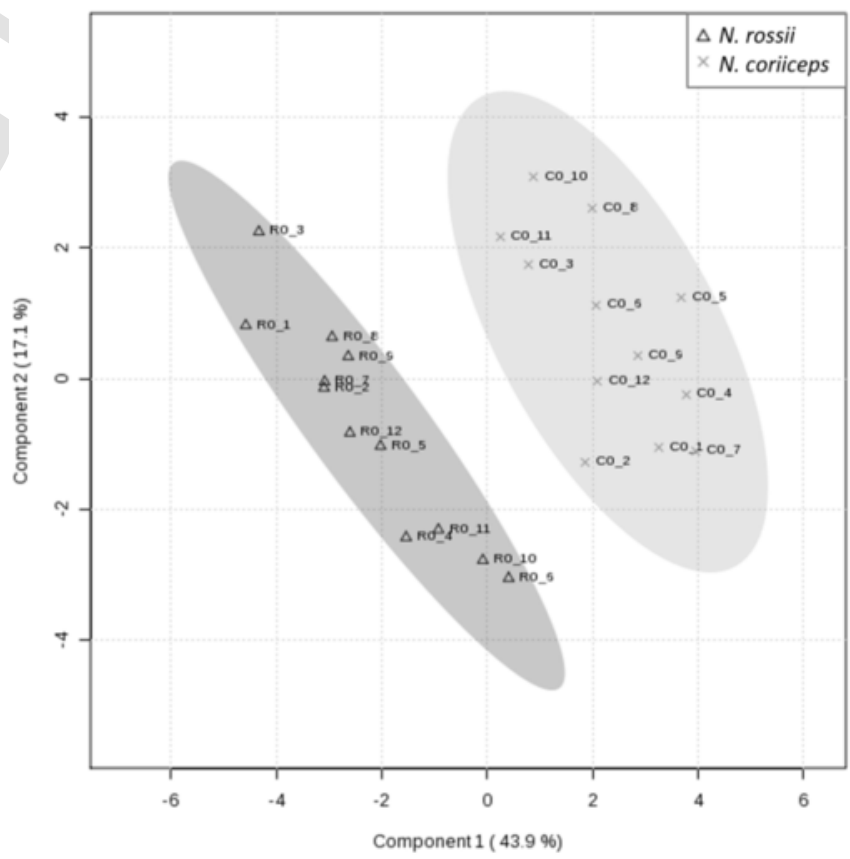

Fig. 2. A. Principal component analysis (PCA) of the normalised concentrations of assigned metabolites in the control groups acclimated to $0{ }^{\circ}$ C.B. Score Plot of the PLS-DA model for the normalised concentrations of assigned metabolites from gill tissue extracts in control groups of the two Antarctic fish species acclimated to $0{ }^{\circ} \mathrm{C}$. Ellipses correspond to a confidence interval of $95 \%$ for each group.

A general pattern of metabolite responses in gill tissues was that in warm-acclimated $N$. rossii more amino acids displayed significantly lower concentrations than in $N$. coriiceps (see Table 3). Although the absolute concentrations of all these metabolites were lowered in $N$. 
Table 2

Metabolites of gills showing significant change in the normalised concentration values in Notothenia coriiceps (NC) in comparison to Notothenia rossii (NR) (control groups, acclimated to $0{ }^{\circ} \mathrm{C}$ ).

\begin{tabular}{|c|c|c|c|c|}
\hline Amino acids & & & & \\
\hline Methionine & NR & $>$ & NC & $P<0.05$ \\
\hline Phenylalanine & NR & $>$ & NC & $P<0.01$ \\
\hline Tyrosine & NR & $>$ & NC & $P<0.001$ \\
\hline \multicolumn{5}{|l|}{ Organic osmolytes } \\
\hline Dimethylamine & NR & $>$ & NC & $\mathrm{P}<0.01$ \\
\hline TMAO & NR & $<$ & NC & $P<0.001$ \\
\hline \multicolumn{5}{|l|}{ Energy metabolism } \\
\hline Creatine/phosphate & NR & $>$ & NC & $\mathrm{P}<0.001$ \\
\hline Glucose & NR & $>$ & NC & $\mathrm{P}<0.001$ \\
\hline NADH/NADPH & NR & $>$ & NC & $\mathrm{P}<0.001$ \\
\hline Citrate & NR & $>$ & NC & $\mathrm{P}<0.05$ \\
\hline \multicolumn{5}{|c|}{ Phospholipid related compounds } \\
\hline Choline & NR & $>$ & NC & $\mathrm{P}<0.001$ \\
\hline Glycerophosphocholine & NR & $>$ & NC & $\mathrm{P}<0.01$ \\
\hline \multicolumn{5}{|l|}{ Miscellaneous } \\
\hline Acetate & NR & $>$ & NC & $\mathrm{P}<0.01$ \\
\hline Inosine & NR & $<$ & NC & $\mathrm{P}<0.05$ \\
\hline Sarcosine & NR & $>$ & $\mathrm{NC}$ & $\mathrm{P}<0.001$ \\
\hline
\end{tabular}

$P$-values determined using t-test and Mann-Whitney Rank Sum test, if prior Equal Variance test failed.

coriiceps as well, these changes did not prove to be significant, except for glycine. Finally, the Krebs cycle intermediate succinate increased significantly in gill tissue samples collected from the $5{ }^{\circ} \mathrm{C}$ acclimated animals in $N$. rossii, but not in those from $N$. coriiceps (see Fig. 5).

\section{Discussion}

Aim of this study was to discover changes and differences of the metabolic profiles of two closely related Antarctic notothenioids, the Antarctic rock cod Notothenia rossii and the Antarctic yellow rock cod Notothenia coriiceps after three months incubation at $5{ }^{\circ} \mathrm{C}$. This degree of warming has been projected for Antarctic surface waters around King George Island in the year 2100. The study focuses on major pat-

\section{A}

\section{Notothenia rossii}

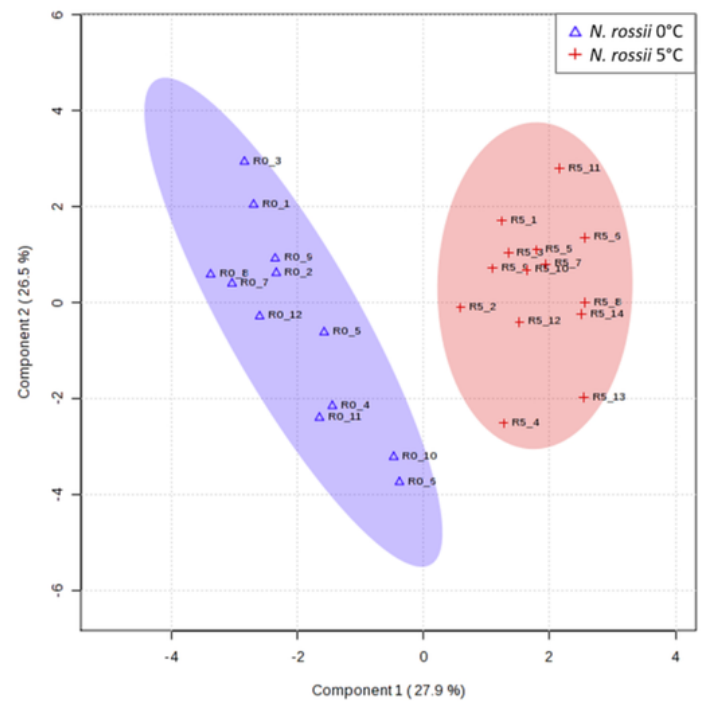

terns, especially in the amino acid metabolism, and cannot explain all discovered differences in detail, because of the complexity of the total metabolic profile.

\subsection{Identified metabolites}

The gill tissue is a metabolically active tissue requiring $7 \%$ of a fish's total oxygen demand, which is met by the direct oxygen uptake of gill filaments (Mommsen, 1984). Other important functions are osmoregulation, acid-base regulation and excretion of nitrogenous waste (Mommsen, 1984). All metabolite classes used in normal cell metabolism, such as sugars, proteins, nucleotides and lipids are present in gill tissues. Additionally, metabolites occur that are necessary to fulfil specific functions, such as osmolytes or glycoproteins.

The spectrum obtained from $N$. rossii (Fig. 1) was dominated by signals of osmolytes, such as taurine and TMAO, and free amino acids, such as alanine, glutamate and glycine. This finding is in line with ${ }^{1} \mathrm{H}-\mathrm{NMR}$ studies on gill tissue extracts of other marine organisms, which also reported these metabolite groups as the most dominant (e.g. Tikunov et al., 2010; Liu et al., 2011; Xu et al., 2015).

Metabolites were grouped in different classes in order to identify major trends in cell metabolism.

1. The free amino acids: alanine, glutamate, glutamine, glycine, histidine, isoleucine, leucine, methionine, phenylalanine, tyrosine and valine found in both notothenioids were also those identified in ${ }^{1} \mathrm{H}-\mathrm{NMR}$ spectra of other marine fish and mussel gill tissues (Tikunov et al., 2010; $\mathrm{Xu}$ et al., 2015). Besides being used in protein and keton synthesis, such amino acids are used as an energy source through oxidation. The rate of amino acids catabolism is usually high in fish, a finding related to a protein-rich diet (Mommsen, 1984). Nevertheless, investigations on aerobic metabolism in tilapia and toadfish revealed that gill cells in both species oxidise glucose and lactate at even larger rates than alanine or oleate (Perry and Walsh, 1989). Furthermore, amino acids are used for gluconeogenesis, lipogenesis and can act as osmolytes (Ballantyne, 2001; Yancey, 2005).

In the present study the highest concentrations were found for alanine and glutamate, which are described as good substrates for gluconeogenesis (Van Waarde, 1983).

2. Metabolites related to energy metabolism/Krebs cycle intermediates: glucose and lactate are used in oxidative metabolism as main en-

B

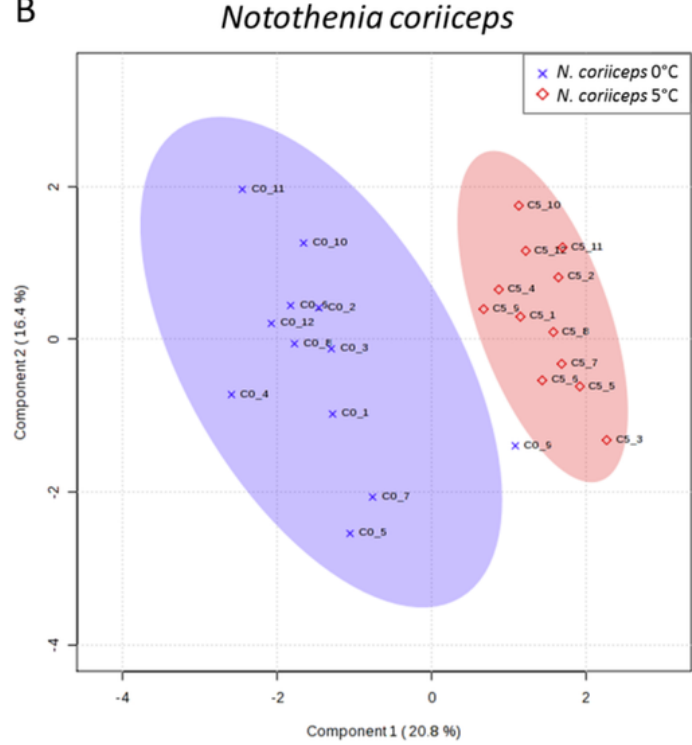

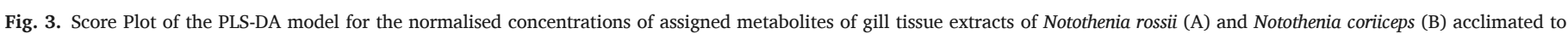
$0{ }^{\circ} \mathrm{C}$ and $5{ }^{\circ} \mathrm{C}$. Ellipses correspond to a confidence interval of $95 \%$ for each group. 
Table 3

Gill metabolites showing significant changes after acclimation from 0 to $5{ }^{\circ} \mathrm{C}$ in each species. Significance levels were analysed using normalised concentrations.

\begin{tabular}{|c|c|c|c|c|c|}
\hline N. rossii & & & N. coriiceps & & \\
\hline \multicolumn{6}{|l|}{ Amino acids } \\
\hline Glutamate & $\downarrow$ & $\mathrm{P}<0.05$ & & & \\
\hline Glycine & $\downarrow$ & $\mathrm{P}<0.05$ & Glycine & $\downarrow$ & $\mathrm{P}<0.05$ \\
\hline Histidine & $\uparrow$ & $\mathrm{P}<0.05$ & & & \\
\hline Leucine & $\downarrow$ & $\mathrm{P}<0.01$ & & & 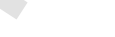 \\
\hline Methionine & $\downarrow$ & $\mathrm{P}<0.05$ & & & \\
\hline Tyrosine & $\downarrow$ & $\mathrm{P}<0.001$ & & & \\
\hline \multicolumn{6}{|l|}{ Organic osmolytes } \\
\hline \multirow[t]{2}{*}{ Betaine } & $\downarrow$ & $\mathrm{P}<0.001$ & & & \\
\hline & & & Dimethylamine & $\downarrow$ & $\mathrm{P}<0.05$ \\
\hline TMAO & $\downarrow$ & $\mathrm{P}<0.001$ & TMAO & $\downarrow$ & $\mathrm{P}<0.001$ \\
\hline \multicolumn{6}{|l|}{ Energy metabolism } \\
\hline Succinate & $\uparrow$ & $\mathrm{P}<0.05$ & & & \\
\hline \multicolumn{6}{|c|}{ Phospholipid related compounds } \\
\hline Choline & $\downarrow$ & $\mathrm{P}<0.05$ & Choline & $\downarrow$ & $\mathrm{P}<0.05$ \\
\hline Glycerophosphocholine & $\downarrow$ & $\mathrm{P}<0.01$ & & & \\
\hline myo-Inositol & $\downarrow$ & $\mathrm{P}<0.001$ & myo-Inositol & $\downarrow$ & $\mathrm{P}<0.01$ \\
\hline \multicolumn{6}{|l|}{ Miscellaneous } \\
\hline \multirow[t]{3}{*}{ Acetate } & $\downarrow$ & $\mathrm{P}<0.001$ & Acetate & $\downarrow$ & $\mathrm{P}<0.01$ \\
\hline & & & Anserine & $\downarrow$ & $\mathrm{P}<0.01$ \\
\hline & & & Dimethylsulfone & $\uparrow$ & \\
\hline Inosine & $\uparrow$ & $\mathrm{P}<0.001$ & Inosine & $\uparrow$ & $\mathrm{P}<0.01$ \\
\hline Putrescine & $\downarrow$ & $\mathrm{P}<0.001$ & & & \\
\hline Sarcosine & $\downarrow$ & $\mathrm{P}<0.05$ & & & \\
\hline
\end{tabular}

P-values determined using t-test and Mann-Whitney Rank Sum test, if prior Equal Variance test failed.

\section{Groups acclimated to $5^{\circ} \mathrm{C}$}

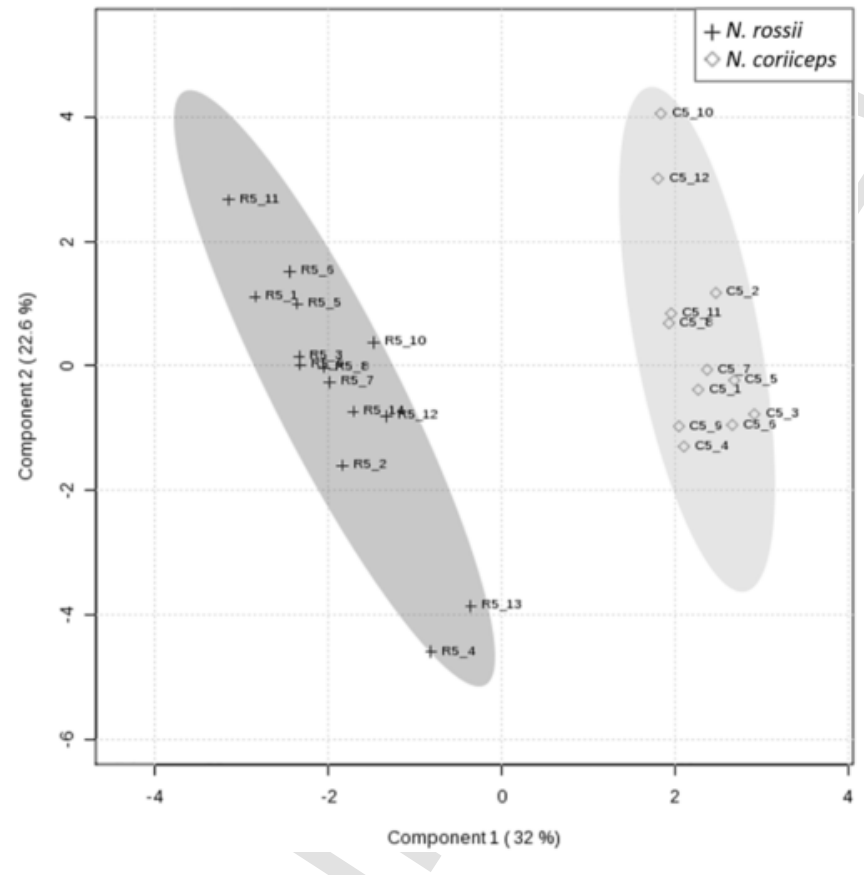

Fig. 4. PLS-DA Score plot for the normalised concentrations of assigned metabolites from gill tissue extracts of notothenioids acclimated to $5{ }^{\circ} \mathrm{C}$. Ellipses correspond to a confidence interval of $95 \%$ for each group.

ergy source. These two and other assigned metabolites play major roles in various pathways of energy metabolism, such as creatine and phosphocreatine and the nucleotide derivatives ADP, ATP, NADH, NADPH.
All metabolites are commonly present in ${ }^{1} \mathrm{H}-\mathrm{NMR}$ spectra of various tissues from ectothermic animals (Mannina et al., 2008; Nestor et al., 2010; Tikunov et al., 2010; Lardon et al., 2013; Koyama et al., 2015).

Since the gills are a highly oxidative tissue, the Krebs cycle intermediates citrate and succinate were detected in gill tissue extracts, as shown in other studies (Lannig et al., 2010; Liu et al., 2011; Zhang et al., 2011).

Acetate is another metabolite that plays a decisive role in the metabolism of cells, as acetyl-CoA in the Krebs-cycle or as a precursor of lipids (Dean, 1969). Acetate was also found in aqueous gill extracts of goldfish (Xu et al., 2015).

3. Structural compounds: choline, inositol and ethanolamine are head groups for phospholipids and thus play a major role in the structural composition of membranes, as do the metabolites phosphocholine and glycerophosphocholine (Tocher et al., 2008). These essential structural components occur in almost all cells and were found in many gill tissues, for example in goldfish (Xu et al., 2015) and clams (Koyama et al., 2015).

4. Osmolytes: marine fishes actively regulate the osmotic gradient by active ion excretion across the gills and use small organic osmolytes as compatible solutes to maintain the intracellular homeostasis. Organic osmolytes have further functions, such as metabolic protection or stabilisation of macromolecules (Yancey, 2005). Among the osmolytes detected in gill tissue extracts were the methylamines TMAO, betaine and DMA, which are able to enhance protein folding and ligand binding. The dipeptide taurine has antioxidant and membrane stabilising activities (Roysommuti et al., 2003; Yancey, 2005). Taurine and TMAO occurred in exceptionally high concentrations in gill tissues of both notothenioids. While taurine is reported to occur in many organisms and different tissue types (Solís et al., 1988; Miller et al., 2000; Yancey, 2005; Kabli et al., 2009), high amounts of TMAO were found in several marine as well as Antarctic teleost fish. Antarctic fish have a higher os- 


\section{Methionine}

N. rossii

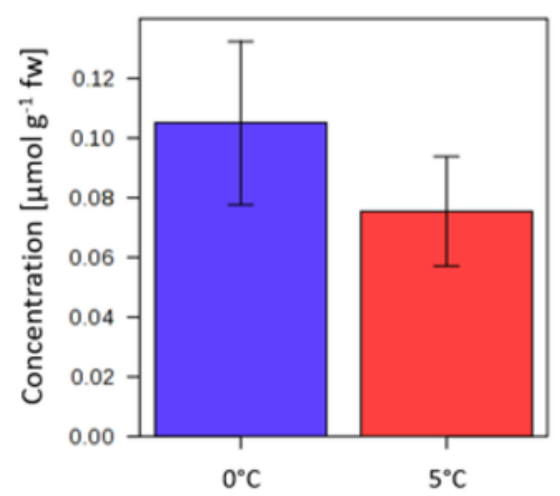

N. coriiceps

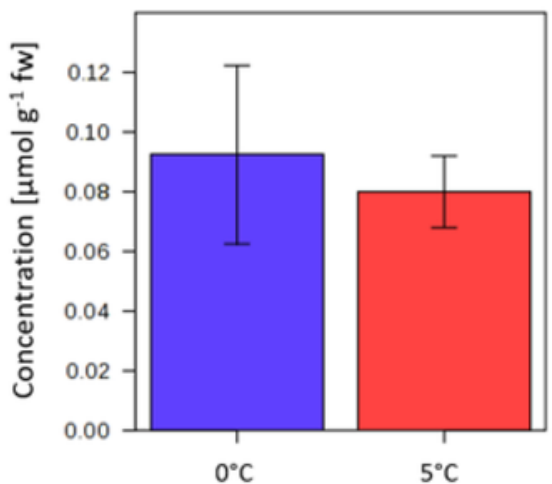

Tyrosine

N. rossii

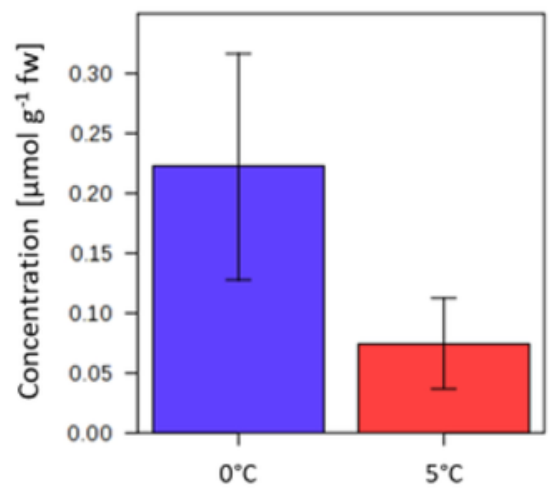

N. coriiceps

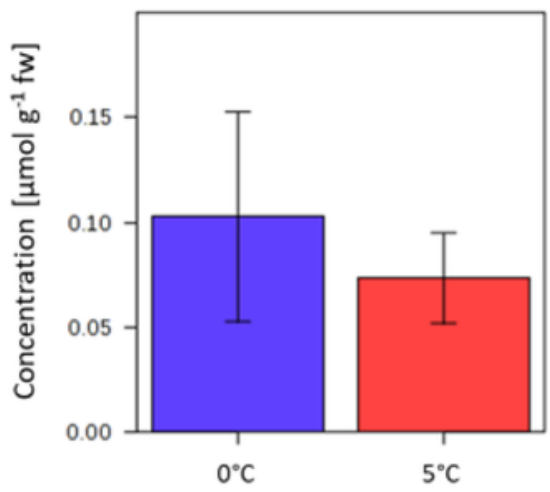

\section{Succinate}

N. rossii

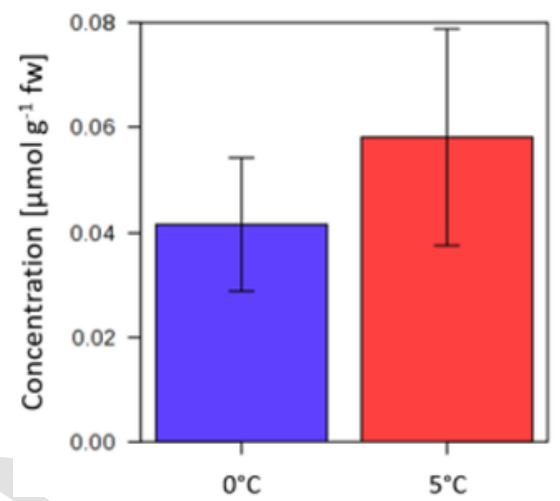

N. coriiceps

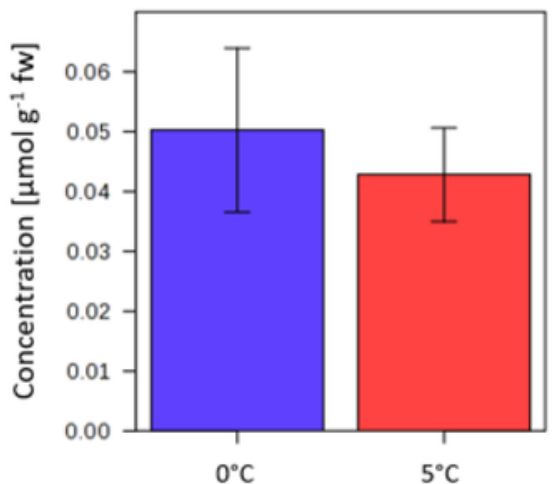

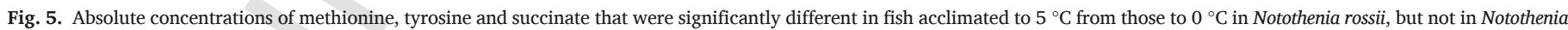
coriiceps. Significant changes were analysed using normalised metabolite concentrations. Note that the ordinates differ in scale.

molality than temperate fish, possibly reflecting cold adaption. High amounts of TMAO contribute to this high osmolality (Raymond and DeVries, 1998).

5. Miscellaneous metabolites: Several other detected metabolites with miscellaneous functions have been identified in other studies of aqueous gill extracts as well, such as the antioxidant glutathione and the purine derivatives inosine and hypoxanthine (Xu et al., 2015). Malonate was also found in gills of Manila clam (Zhang et al., 2011) and putrescine in gills of the clam Corbicula japonica (Koyama et al., 2015). In addition, some signals could not be assigned to a specific metabolite. For example, the signal at $3.35 \mathrm{ppm}$ might be attributed to scyllo-inositol (Michaelis et al., 1993), that functions as a compatible osmolyte in 
deep-sea animals (Yancey, 2005). Further studies using analytical methods, such as mass spectrometry techniques or Fourier transform infrared spectroscopy (Dunn and Ellis, 2005) are necessary to characterise this metabolite and the other unknown compounds in order to gain knowledge about their functional role in cells.

The absolute metabolite concentrations determined from ${ }^{1} \mathrm{H}-\mathrm{NMR}$ spectra in the gill tissues of both species are well in the range of concentrations reported in the literature, indicating the reliability of the used technique. Picone et al. (2011) found comparable amounts of the amino acids leucine and glycine and other metabolites, such as hypoxanthine and inosine, in muscle extracts of Gilthead sea bream (Sparus aurata). In addition, similar concentrations of some of the amino and organic acids were reported in gill tissues of flatfish using ${ }^{1} \mathrm{H}-\mathrm{NMR}$ spectroscopy and gas chromatography (Fan et al., 1993).

\subsection{Differences in the metabolite profiles of the two Antarctic notothenioids}

The similarity of the ${ }^{1} \mathrm{H}-\mathrm{NMR}$ spectra of both Antarctic notothenioids may reflect the close relationship of the two notothenioids (Near et al., 2004; Near and Cheng, 2008). This makes them ideal candidates for a comparison of their metabolite profiles in association with the ecological diversification related to differences in their lifestyle (e.g. benthic versus bentho-pelagic).

For control animals, a functional differentiation of the two Antarctic notothenioids according to metabolite concentrations in gill tissue extracts is supported by the PLS-DA score plot (Fig. 2B). The associated differences in the metabolite concentrations are presented in Table 2 and show that Notothenia rossii has significantly higher concentrations of the amino acids methionine, phenylalanine and tyrosine. Phenylalanine is a precursor of tyrosine and both are used for protein synthesis. $N$. rossii exhibited also higher concentrations in energy related metabolites and of phospholipid related compounds. On the other hand, $N$. coriiceps has significantly higher TMAO and inosine levels in gill cells, but less sarcosine.

The higher amounts of metabolites associated with energy metabolism, such as NADH and NADPH or phosphocreatine, point to a higher energy turnover of $N$. rossii in comparison to $N$. coriiceps. This finding supports the more active lifestyle found in the bentho-pelagic living $N$. rossii. In contrast, Notothenia coriiceps uses only $5.7 \%$ of its total metabolic rate for activity and feeding (Campbell et al., 2007) and locomotory activity was detected for only $1.7 \%$ of a day (North, 1996). Additionally, it was suggested that $N$. coriiceps individuals from Potter Cove remain nearshore during their whole life cycle without migrating to offshore waters for feeding or breeding ( $\mathrm{N}$. Koschnick, personal communication). In contrast, $N$. rossii migrate offshore to feed and reproduce, which may come with a higher energy demand due to repeated active swimming (Casaux et al., 1990; Webb, 1971). This higher energy demand is reflected in a higher basal metabolism in $N$. rossii than in other less active notothenioids (Morris and North, 1984).

Among Antarctic notothenioids, which lack swim bladders, a trend is observed that more pelagic species have higher lipid contents and therefore also higher total amounts of phospholipids than benthic species (Clarke et al., 1984; Hagen et al., 2000). The higher concentration of choline and phospho-di- and mono-ester, which are used as head group for phospholipids, would support this hypothesis for the more pelagic $N$. rossii. Future studies on lipid composition, especially in lipid-rich compartments like liver or red muscles (Clarke et al., 1984) are needed to confirm this.

The TMAO concentration was almost twice as high in $N$. coriiceps as $N$. rossii, while the concentration of DMA and another methylamine sarcosine, was significantly higher in $N$. rossii. Sarcosine has also been demonstrated to play a role as an organic osmolyte in some marine organisms (Van Waarde, 1988). TMAO is the major compatible solute typically found in many marine organisms including fishes and can also counteract the effect of hydrostatic pressure on enzyme function (Seibel and Walsh, 2002; and references herein). A varying intracellular composition of organic osmolytes might account for the observed differences in concentrations of these metabolites between both notothenioid species. Overall, the TMAO concentration is one to two orders of magnitude higher than of the other two osmolytes, so it is most unlikely fully compensated by the other metabolites. The accumulation of TMAO in marine organisms is still unclear and its specific role in notothenioids needs to be unravelled (Seibel and Walsh, 2002).

\subsection{Acclimation processes to warming}

The main changes observed in the metabolite concentrations of gill tissue extracts acclimated to $5{ }^{\circ} \mathrm{C}$ in comparison to the control group are a decrease in amino acids and a decline in metabolites related to lipid metabolism for both species. Reduced amounts of free amino acids were also found in long-term warm-acclimated Atlantic salmon (Kullgren et al., 2013), as were lipid related compounds. In addition, our results revealed lower concentrations of organic osmolytes in the warm-acclimated groups (Table 3). As expected, long term acclimation to elevated temperatures induced changes in amino acids in the gill tissue. The reduced cytosolic amounts of glycine in both species and the lower amounts of other amino acids in warm-acclimated $N$. rossii reflect an increased demand or turnover.

Amino acids can be used for protein synthesis and energy production by catabolism. While Kullgren et al. (2013) proposed a particular need for specific amino acids that were significantly lower in warm-acclimated Atlantic salmon, an increased overall demand for amino acids is also conceivable. Increasing protein damage at higher temperatures (Somero, 1995), especially in Antarctic fish with specific cold adapted protein synthesis mechanisms (Peck, 2016), might cause the higher demand for amino acids in the warm-acclimated notothenioid group in order to synthesise new functional proteins compensating for the damage. The decreased amino acids might even be related to the synthesis of heat-shock proteins, which were described as a nearly universal cellular response to elevated temperatures. These proteins stabilise other functionally relevant proteins, prevent aggregation of denatured proteins and help denatured proteins to re-fold into functional states (Feder and Hofmann, 1999). Despite the universal finding of the heat shock response (HSR), for example in notothenioids from New Zealand, there was no evidence for a heat-induced HSR in other Antarctic notothenioids (Hofmann et al., 2000; Hofmann et al., 2005). As there is no simple rule for possession and expression or loss of the classical heat shock response in Antarctic marine organisms (Clark and Peck, 2009), further studies need to address the question, whether some Antarctic species are able to show a HSR at elevated water temperatures. However, overall lower growth rates, which were found in long-term warm-acclimated Antarctic eelpout (Windisch et al., 2014), come along with lower rates of protein biosynthesis.

Besides the obvious role of amino acids in protein synthesis, free amino acids can also fuel the carbohydrate metabolism at higher temperatures. The degradation of branch-chain amino acids (BCAA), such as isoleucine, leucine and valine, leads to succinyl CoA, an intermediate of the tricarboxylic acid (TCA) cycle and glucogenic compounds that facilitates gluconeogenesis (Harvey and Ferrier, 2011). Those branched amino acids occur in lower concentrations in both species at warmer temperatures (data not shown, see Supplementary S3), which might be the result of a metabolic shift to carbohydrate-based metabolism, as indicated in the Antarctic eelpout to warming (Windisch et al., 2014). In the same study Windisch et al. proposed the importance of the glycine metabolism at low temperatures, since a strong temperature dependency in the expression of the glycine cleavage system was found in Antarctic eelpout. Indeed, glycine concentrations were reduced in both species acclimated to $5^{\circ} \mathrm{C}$. Whether the glycine cleavage 
system serves at low temperatures the catabolism of excessive glycine or rather its anabolism needs still to be investigated in future studies.

In the gill extracts the decrease in amino acids is more pronounced in $N$. rossii, which indicates a higher demand at $5{ }^{\circ} \mathrm{C}$ in comparison to N. coriiceps.

During thermal acclimation, the concentration of choline and myo-inositol in gill tissue were significantly decreased. In addition, a significant decrease of glycerophosphocholine was observed in $N$. rossii. These metabolites are used as structural components of phospholipids and can therefore be related to membrane changes. A decrease of the head groups in the cytosolic fraction might point to an elevated production of phospholipids and membrane elements. This explanation was suggested by lower choline concentrations found in warm-acclimated Atlantic salmon (Kullgren et al., 2013) and was also observed after long term acclimation to warming in the brain tissue of two gadid fish species (Schmidt et al., 2017). The increased building of structural membrane components is in line with the concept of homeoviscous adaptation, which states that membrane structures are remodelled at altered temperatures to compensate for harmful changes in the fluidity of membranes. During cold adaption more unsaturated fatty acids are incorporated in membranes to keep them fluid even at cold ambient temperatures. With rising temperatures, the membrane will become too disordered and will lose its integrity (Moyes and Ballantyne, 2011). The preferential synthesis of phosphocholine compared to phosphoethanolamine at higher temperatures discovered by Hazel and Williams (1990) is also reflected in our observations. While the amount of choline in the cytoplasm decreased significantly, ethanolamine concentrations did not change in the $5{ }^{\circ} \mathrm{C}$ acclimated groups. The increased synthesis of gill membranes in the warmth might also favour a better gas exchange due to increased surface area of gill cells. This could enhance the oxygen supply capacity of the gill tissue to enhance oxygen supply at rising temperatures (Allen, 1955; Pörtner and Peck, 2010).

While amino acids and phospholipid metabolism components change, the glucose concentration remained stable in all gill extracts. This is congruent with the observed steady state concentration of glucose in the plasma of Antarctic notothenioids (Pagothenia borchgrevinki and Trematomus bernacchii) acclimated to $4{ }^{\circ} \mathrm{C}$ (Lowe and Davison, 2005). Organic osmolytes concentrations, such as TMAO, were reduced in gills after long-term acclimation to higher temperatures. This was also reported for fish brain upon warming (Schmidt et al., 2017). The high osmolarity usually found in cold adapted fish for reducing the freezing point (Scholander et al., 1957) is decreased upon warming, resulting in the observed decrease in the organic osmolytes TMAO and myo-inositol, which serve as cryo-protectants in cold environments (Treberg et al., 2002; Vesala et al., 2012). In addition, a higher activity of ion transporters like the sodium-potassium ATPase at warmer temperatures will lead to decreased organic osmolytes. Strobel et al. (2012) observed a decreasing serum osmolarity in notothenioids due to warm acclimation. Intracellular osmolarity is then obtained by adjusting inorganic ions and the amount of organic osmolytes (Hochachka and Somero, 2002).

\subsection{Differences in the acclimation capacities of the two notothenioid species}

While both notothenioid species shared significant changes in their metabolite profiles due to higher temperature, Table 3 illustrates that $N$. rossii showed overall more significant changes than $N$. coriiceps. Especially the concentration of amino acids, such as glutamate, methionine, leucine or tyrosine were lower in $N$. rossii acclimated to $5{ }^{\circ} \mathrm{C}$ than in its sister species. Glycine was the only amino acid that decreased in both species, which might be due to the specific importance of glycine at low temperatures, as proposed by its role in the glycine cleavage system (Windisch et al., 2014). In N. rossii, the lower levels of other amino acids in the cytosol and thus the resulting higher demand for substrate, emphasise the above-mentioned overall need for more amino acids. The amino acids are most likely used for energy production by catabolism in the gills (see above), which suggests a higher thermal energy demand of $N$. rossii in comparison to $N$. coriiceps. Klein et al. (2017) reported higher activities of enzymes involved in reactive oxygen detoxification and glutathione production in gill tissue of $N$. rossii in order to keep levels of oxidative damage similar to those observed in the rockcod $N$. coriiceps. The maintenance of high enzyme activities comes along with energetic costs and would be another factor influencing the performance capacities of Notothenia rossii.

The significantly higher amount of succinate in warm-acclimated $N$. rossii reinforce this hypothesis. Succinate can indicate mitochondrial anaerobiosis (Grieshaber et al., 1994). The onset of anaerobiosis leads to time limited survival of organism at critical temperatures (Pörtner, 2001). Succinate was shown to accumulate in tissues exposed to temperatures above the critical temperature in crustaceans (Frederich and Pörtner, 2000) and was also found to accumulate in Antarctic eelpout or Antarctic bivalves at critical temperatures (Pörtner et al., 1999; van Dijk et al., 1999).

The accumulation of succinate indicates a narrower temperature window of $N$. rossii than $N$. coriiceps where some metabolic processes in gills have reached their limit already at $5{ }^{\circ} \mathrm{C}$. This assumption is supported by the finding that among cold-adapted notothenioids Notothenia rossii has only a moderate scope for acclimation and tolerance towards ocean acidification and warming. Strobel et al. (2013a, 2013b) proposed poor acclimation capacity based on routine metabolic rate, mitochondrial respiration capacities and mitochondrial enzyme activities of long-term acclimated individuals reflecting whole animal performance. In addition, uncompensated mitochondrial respiration rates that may reflect a high oxygen and metabolic demand at tissue level, have been found in $N$. rossii acclimated to $7{ }^{\circ} \mathrm{C}$, while the more sub-Antarctic notothenioid Lepidonotothen squamifrons have shown partial compensation of mitochondrial respiration rates (Strobel et al., 2012; Strobel et al., 2013a). Taken together the observed changes in metabolite concentrations and the shifts in metabolic performance detected in other studies (Strobel et al., 2012, 2013a, 2013b; Klein et al., 2017) point to a higher thermal sensitivity of $N$. rossii compared to $N$. coriiceps.

\section{Conclusions}

In conclusion, the two Antarctic notothenioid species Notothenia rossii and Notothenia coriiceps are able to survive at temperatures about $3{ }^{\circ} \mathrm{C}$ higher than their ambient summer habitat temperatures. However, based on this metabolic approach and previous studies $N$. rossii seem to be more sensitive to warming than $N$. coriiceps. Untargeted NMR based metabolic profiling revealed significant changes in metabolite concentrations in gill tissue after long-term acclimation to elevated temperatures, while the metabolite composition remains unchanged in both species. The observed decrease in the amino acid concentrations was related to an enhanced catabolism in the gills, a finding that was also seen in brain tissues of polar fish. This might have, together with an increased protein degradation and the higher energy demand for restructuring cellular membranes, fatal consequences for notothenioids in the near future.

Supplementary data to this article can be found online at https:// doi.org/10.1016/j.cbpa.2017.12.012. 


\section{Ethical approval}

The experiments conducted were in accordance with the ethical standards of the federal state of Bremen, Germany, and were approved under reference number 522-27-11/02-00 (93).

\section{Uncited reference}

\section{Acknowledgements}

We thank Nils Koschnick for conducting the acclimation experiment and providing the sample material. Furthermore, we thank Rolf-Markus Wittig for his assistance during the NMR measurements. Kai Wätjen for catching and taking care of the animals on King George island. Katja Mintenbeck, Timo Hirse and Tina Sandersfeld for taking care of the animals during the ANTXXVII-4 cruise. This work is a contribution to the research program "Polar regions and coasts in a changing Earth system" (PACES) of the Alfred Wegener Institute.

\section{References}

Allen, J.A., 1955. Solubility of Oxygen in Water. Nature https://doi.org/10.1038/ $175083 \mathrm{a} 0$.

Ballantyne, J.S., 2001. Amino acid metabolism. In: Wright, P.A., Anderson, P.M. (Eds.), Fish Physiology: Nitrogen Excretion. Academic Press, pp. 77-108.

Bilyk, K.T., DeVries, A.L., 2011. Heat tolerance and its plasticity in Antarctic fishes. Comp. Biochem. Physiol. A Mol. Integr. Physiol. 158, 382-390. https://doi.org/10.1016/j. cbpa.2010.12.010.

Bock, C., Sartoris, F.J., Wittig, R.M., Pörtner, H.O., 2001. Temperature-dependent pH regulation in stenothermal Antarctic and eurythermal temperate eelpout (Zoarcidae): an in-vivo NMR study. Polar Biol. 24, 869-874. https://doi.org/10.1007/ s003000100298.

Campbell, H.A., Fraser, K.P.P., Peck, L.S., Bishop, C.M., Egginton, S., 2007. Life in the fast lane: The free-ranging activity, heart rate and metabolism of an Antarctic fish tracked in temperate waters. J. Exp. Mar. Biol. Ecol. 349, 142-151. https://doi.org/10.1016/ j.jembe.2007.05.009.

Canioni, P., Quistorff, B., 1994. Liver physiology and metabolism. In: NMR in Physiology and Biomedicine. pp. 373-388.

Casaux, R.J., Mazzotta, A.S., Barrera-Oro, E.R., 1990. Seasonal aspects of the biology and diet of nearshore nototheniid fish at Potter Cove, South Shetland Islands, Antarctica. Polar Biol. 11, 63-72. https://doi.org/10.1007/BF00236523.

Castejón, D., Villa, P., Calvo, M.M., Santa-María, G., Herraiz, M., Herrera, A., 2010. 1H-HRMAS NMR study of smoked Atlantic salmon (Salmo salar). Magn. Reson. Chem. 48, 693-703. https://doi.org/10.1002/mrc.2652.

Clark, M.S., Peck, L.S., 2009. HSP70 heat shock proteins and environmental stress in Antarctic marine organisms: A mini-review. Mar. Genomics 2, 11-18. https://doi.org/ 10.1016/j.margen.2009.03.003.

Clarke, A., Doherty, N., Devries, A.L., Eastman, J.T., Survey, B.A., Cross, H., Road, M., Cb, C., 1984. Lipid content and composition of three species of Antarctic fish in relation to buoyancy. Polar Biol. 3, 77-83.

Craig, A., Cloarec, O., Holmes, E., Nicholson, J.K., Lindon, J.C., 2006. Scaling and normalization effects in NMR spectroscopic metabonomic data sets. Anal. Chem. 78, 2262-2267. https://doi.org/10.1021/ac0519312.

Dean, J.M., 1969. The metabolism of tissues of thermally acclimated trout (Salmo Gairdneri). Comp. Biochem. Physiol. 29, 185-196.

van Dijk, P.L., Tesch, C., Hardewig, I., Portner, H., 1999. Physiological disturbances at critically high temperatures: a comparison between stenothermal antarctic and eurythermal temperate eelpouts (Zoarcidae). J. Exp. Biol. 202 (Pt 24), 3611-3621.

Dunn, W.B., Ellis, D.I., 2005. Metabolomics: Current analytical platforms and methodologies. TrAC Trends Anal. Chem. 24, 285-294. https://doi.org/10.1016/j.trac.2004.11. 021.

Fan, T.W.-M., 1996. Metabolite profiling by one- and two-dimensional NMR analysis of complex mixtures. Prog. Nucl. Magn. Reson. Spectrosc. 28, 161-219. https://doi.org/ 10.1016/0079-6565(95)01017-3.

Fan, T.W.-M., Colmer, T.D., Lane, A.N., Higashi, R.M., 1993. Determination of metabolites by $1 \mathrm{H}$ NMR and GC: analysis for organic osmolytes in crude tissue extracts. Anal. Biochem. 214, 260-271.

Feder, M.E., Hofmann, G.E., 1999. Heat-shock proteins, molecular chaperones, and the stress response: evolutionary and ecological physiology. Annu. Rev. Physiol. 61, 243-282. https://doi.org/10.1146/annurev.physiol.61.1.243.

Frederich, M., Pörtner, H.O., 2000. Oxygen limitation of thermal tolerance defined by cardiac and ventilatory performance in spider crab, Maja squinado. Am. J. Phys. Regul. Integr. Comp. Phys. 279, R1531-R1538.

Gonzalez-Cabrera, P.J., Dowd, F., Pedibhotla, V.K., Rosario, R., Stanley-Samuelson, D., Petzel, D., 1995. Enhanced hypo-osmoregulation induced by warm-acclimation in antarctic fish is mediated by increased gill and kidney $\mathrm{Na}+/ \mathrm{K}(+)$-ATPase activities. $\mathrm{J}$. Exp. Biol. 198, 2279-2291.

Gribbestad, I.S., Aursand, M., Martinez, I., 2005. High-resolution 1H magnetic resonance spectroscopy of whole fish, fillets and extracts of farmed Atlantic salmon (Salmo salar) for quality assessment and compositional analyses. Aquaculture 250, 445-457. https: //doi.org/10.1016/j.aquaculture.2005.02.031.

Grieshaber, M.K., Hardewig, I., Kreutzer, U., Pörtner, H.O., 1994. Physiological and metabolic responses to hypoxia in invertebrates. Rev. Physiol. Biochem. Pharmacol. 125, 43-147. https://doi.org/10.1007/BFb0030909.

Guderley, H., 2004. Metabolic responses to low temperature in fish muscle. Biol. Rev. 79, 409-427.

Hagen, W., Kattner, G., Friedrich, C., 2000. The lipid compositions of high-Antarctic notothenioid fish species with different life strategies. Polar Biol. 23, 785-791. https:// doi.org/10.1007/s003000000153.

Harvey, R.A., Ferrier, D.R., 2011. Biochemistry. Lippincott Williams \& Wilkins.

Hazel, J.R., Williams, E.E., 1990. The role of alterations in membrane lipid composition in enabling physiological adaptation of organisms to their physical environment. Prog. Lipid Res. 29, 167-227. https://doi.org/10.1016/0163-7827(90)90002-3.

Hochachka, P.W., McClelland, G.B., 1997. Cellular metabolic homeostasis during large-scale change in ATP turnover rates in muscles. J. Exp. Biol. 200, 381-386.

Hochachka, P.W., Somero, G.N., 2002. Biochemical Adaptation: Mechanism and Process in Physiological Evolution. Oxford University Press, Oxford.

Hofmann, G.E., Buckley, B.A., Airaksinen, S., Keen, J.E., Somero, G.N., 2000. Heat-shock protein expression is absent in the antarctic fish Trematomus bernacchii (family Nototheniidae). J. Exp. Biol. 203, 2331-2339.

Hofmann, G.E., Lund, S.G., Place, S.P., Whitmer, A.C., 2005. Some like it hot, some like it cold: the heat shock response is found in New Zealand but not Antarctic notothenioid fishes. J. Exp. Mar. Biol. Ecol. 316, 79-89. https://doi.org/10.1016/j.jembe.2004.10. 007.

IPCC Panel, 2014. Climate Change 2014: Synthesis Report.

Kabli, S., Spaink, H.P., De Groot, H.J.M., Alia, A., 2009. In vivo metabolite profile of adult zebrafish brain obtained by high-resolution localized magnetic resonance spectroscopy. J. Magn. Reson. Imaging 29, 275-281. https://doi.org/10.1002/jmri.21609.

Klein, R.D., Rosa, C.E., Colares, E.P., Robaldo, R.B., Martinez, P.E., Bianchini, A., 2017. Antioxidant defense system and oxidative status in Antarctic fishes: the sluggish rockcod Notothenia coriiceps versus the active marbled notothen Notothenia rossii. J. Therm. Biol. https://doi.org/10.1016/j.jtherbio.2017.02.013.

Koyama, H., Okamoto, S., Watanabe, N., Hoshino, N., Jimbo, M., Yasumoto, K., Watabe, S., 2015. Dynamic changes in the accumulation of metabolites in brackish water clam Corbicula japonica associated with alternation of salinity. Comp. Biochem. Physiol. B Biochem. Mol. Biol. 181, 59-70. https://doi.org/10.1016/j.cbpb.2014.11.007.

Kullgren, A., Jutfelt, F., Fontanillas, R., Sundell, K., Samuelsson, L., Wiklander, K., Kling, P., Koppe, W., Larsson, D.G.J., Björnsson, B.T., Jönsson, E., 2013. The impact of temperature on the metabolome and endocrine metabolic signals in Atlantic salmon (Salmo salar). Comp. Biochem. Physiol. A Mol. Integr. Physiol. 164, 44-53. https:// doi.org/10.1016/j.cbpa.2012.10.005.

Lannig, G., Eilers, S., Pörtner, H.O., Sokolova, I.M., Bock, C., 2010. Impact of ocean acidification on energy metabolism of oyster, Crassostrea gigas - changes in metabolic pathways and thermal response. Mar. Drugs 8, 2318-2339. https://doi.org/10.3390/ md8082318.

Lardon, I., Nilsson, G.E., Stecyk, J.A.W., Vu, T.N., Laukens, K., Dommisse, R., De Boeck, G., 2013. 1H-NMR study of the metabolome of an exceptionally anoxia tolerant vertebrate, the crucian carp (Carassius carassius). Metabolomics 9, 311-323. https://doi org/10.1007/s11306-012-0448-y.

Lenz, E.M., Wilson, I.D., 2007. Analytical strategies in metabonomics. J. Proteome Res. 6 , 443-458. https://doi.org/10.1021/pr0605217.

Liu, X., Zhang, L., You, L., Yu, J., Zhao, J., Li, L., Wang, Q., Li, F., Li, C., Liu, D., Wu, H., 2011. Differential toxicological effects induced by mercury in gills from three pedigrees of Manila clam Ruditapes philippinarum by NMR-based metabolomics. Ecotoxicology 20, 177-186. https://doi.org/10.1007/s10646-010-0569-x.

Lowe, C.J., Davison, W., 2005. Plasma osmolarity, glucose concentration and erythrocyte responses of two Antarctic nototheniid fishes to acute and chronic thermal change. J. Fish Biol. 67, 752-766. https://doi.org/10.1111/j.0022-1112.2005.00775.x.

Mannina, L., Sobolev, A.P., Capitani, D., Iaffaldano, N., Rosato, M.P., Ragni, P., Reale, A. Sorrentino, E., D'Amico, I., Coppola, R., 2008. NMR metabolic profiling of organic and aqueous sea bass extracts: Implications in the discrimination of wild and cultured sea bass. Talanta 77, 433-444. https://doi.org/10.1016/j.talanta.2008.07.006.

Mark, F.C., Bock, C., Pörtner, H.O., 2002. Oxygen-limited thermal tolerance in Antarctic fish investigated by MRI and (31)P-MRS. Am. J. Phys. Regul. Integr. Comp. Phys. 283, R1254-R1262. https://doi.org/10.1152/ajpregu.00167.2002.

Michaelis, T., Helms, G., Merboldt, K., Hanicke, W., Bruhn, H., Frahm, J., 1993. Identification of Scyllo-Inositol in Proton. NMR Biomed. 6, 105-109.

Miller, T.J., Hanson, R.D., Yancey, P.H., 2000. Developmental changes in organic osmolytes in prenatal and postnatal rat tissues. Comp. Biochem. Physiol. A Mol. Integr. Physiol. 125, 45-56.

Mommsen, T.P., 1984. 7 Metabolism of the Fish Gill. Fish Physiol. 10, 203-238.

Morris, D.J., North, A.W., 1984. Oxygen consumption of five species from South Georgia. J. Exp. Mar. Biol. Ecol. 78, 75-86.

Moyes, C.D., Ballantyne, J.S., 2011. Membranes and temperature: homeoviscous adaptation. In: Farrell, A. (Ed.), Encyclopedia of Fish Physiology: From Genome to Environment. Elsevier Inc, pp. 1725-1731. 
Near, T.J., Cheng, C.H.C., 2008. Phylogenetics of notothenioid fishes (Teleostei: Acanthomorpha): Inferences from mitochondrial and nuclear gene sequences. Mol. Phylogenet. Evol. 47, 832-840. https://doi.org/10.1016/j.ympev.2007.11.027.

Near, T.J., Pesavento, J.J., Cheng, C.H.C., 2004. Phylogenetic investigations of Antarctic notothenioid fishes (Perciformes: Notothenioidei) using complete gene sequences of the mitochondrial encoded 16S rRNA. Mol. Phylogenet. Evol. 32, 881-891. https:// doi.org/10.1016/j.ympev.2004.01.002.

Nestor, G., Bankefors, J., Schlechtriem, C., BräNnäS, E., Pickova, J., Sandström, C., 2010. High-resolution $1 \mathrm{H}$ magic angle spinning $\mathrm{nmr}$ spectroscopy of intact arctic char (Salvelinus alpinus) muscle. quantitative analysis of n-3 fatty acids, EPA and DHA. J. Agric. Food Chem. 58, 10799-10803. https://doi.org/10.1021/jf103338j.

North, A.W., 1996. Locomotory activity and behaviour of the Antarctic teleost Notothenia coriiceps. Mar. Biol. 126, 125-132. https://doi.org/10.1007/BF00571384.

Peck, L.S., 2016. A cold limit to adaptation in the sea. Trends Ecol. Evol. 31 (1), 13-26. https://doi.org/10.1016/j.tree.2015.09.014.

Perry, S.F., Walsh, P.J., 1989. Metabolism of isolated fish gill cells: contribution of epithelial chloride cells. J. Exp. Biol. 144, 507-520.

Picone, G., Engelsen, S.B., Savorani, F., Testi, S., Badiani, A., Capozzi, F., 2011. Metabolomics as a powerful tool for molecular quality assessment of the fish Sparus aurata. Nutrients 3, 212-227. https://doi.org/10.3390/nu3020212.

Pörtner, H., 2001. Climate change and temperature-dependent biogeography: oxygen limitation of thermal tolerance in animals. Naturwissenschaften 88, 137-146. https://doi. org/10.1007/s001140100216.

Pörtner, H.O., Peck, M.A., 2010. Climate change effects on fishes and fisheries: towards a cause-and-effect understanding. J. Fish Biol. 77, 1745-1779. https://doi.org/10. 1111/j.1095-8649.2010.02783.x.

Pörtner, H.O., Peck, L., Zielinski, S., Conway, L.Z., 1999. Intracellular pH and energy metabolism in the highly stenothermal Antarctic bivalve Limopsis marionensis as a function of ambient temperature. Polar Biol. 22, 17-30. https://doi.org/10.1007/ s003000050386.

Pörtner, H.O., Peck, L., Somero, G., 2007. Thermal limits and adaptation in marine Antarctic ectotherms: an integrative view. Philos. Trans. R. Soc. Lond. Ser. B Biol. Sci. 2233-2258. https://doi.org/10.1098/rstb.2006.1947.

Purohit, P.V., Rocke, D.M., Viant, M.R., Woodruff, D.L., 2004. Discrimination models using variance-stabilizing transformation of metabolomic NMR data. OMICS 8, 118-130. https://doi.org/10.1089/1536231041388348.

Raymond, J.A., DeVries, A.L., 1998. Elevated concentrations and synthetic pathways of trimethylamine oxide and urea in some teleost fishes of McMurdo Sound, Antarctica. Fish Physiol. Biochem. 1, 387-398. https://doi.org/10.1023/A:1007778728627.

Roysommuti, S., Azuma, J., Takahashi, K., Schaffer, S., 2003. Taurine cytoprotection: from cell to system. J. Physiol. Sci. 16, 17-27.

Sandersfeld, T., 2015. Sensitivity of Antarctic fish to ocean warming-an energy budget approach. In: Doctoral dissertation. Alfred Wegener Institute Helmholtz Center for Polar and Marine Research and University of Bremen.

Schmidt, M., Windisch, H.S., Ludwichowski, K.U., Seegert, S.L.L., Pörtner, H.O., Storch, D., Bock, C., 2017. Differences in neurochemical profiles of two gadid species under ocean warming and acidification. Front. Zool. 14 (1), 49. https://doi.org/10.1186/ s12983-017-0238-5

Scholander, P.F., Van Dam, L., Kanwisher, J.W., Hammel, H.T., Gordon, M.S., 1957. Supercooling and osmoregulation in Arctic fish. J. Cell. Physiol. 49 (1), 5-24.

Seibel, B.A., Walsh, P.J., 2002. Trimethylamine oxide accumulation in marine animals: relationship to acylglycerol storage. J. Exp. Biol. 205, 297-306. https://doi.org/10. 1016/0305-0491(95)00108-5.

Sheridan, M.A., 1988. Lipid dynamics in fish: aspects of absorption, transportation, deposition and mobilization. Comp. Biochem. Physiol. B Comp. Biochem. 90 (4), 679-690.

Solís, J.M., Herranz, A.S., Herreras, O., Lerma, J., Martín del Río, R., 1988. Does taurine act as an osmoregulatory substance in the rat brain?. Neurosci. Lett. 91, 53-58. https: //doi.org/10.1016/0304-3940(88)90248-0.

Somero, G.N., 1995. Proteins and Temperature. Annu. Rev. Physiol. 57, 43-68.

Strobel, A., Bennecke, S., Leo, E., Mintenbeck, K., Pörtner, H.O., Mark, F.C., 2012. Metabolic shifts in the Antarctic fish Notothenia rossii in response to rising temperature and PCO2. Front. Zool. 9, 28. https://doi.org/10.1186/1742-9994-9-28.
Strobel, A., Graeve, M., Poertner, H.O., Mark, F.C., 2013. Mitochondrial acclimation capacities to ocean warming and acidification are limited in the Antarctic nototheniid fish, Notothenia rossii and Lepidonotothen squamifrons. PLoS One 8, https://doi.org/ 10.1371/journal.pone.0068865.

Strobel, A., Leo, E., Pörtner, H.O., Mark, F.C., 2013. Elevated temperature and pco2 shift metabolic pathways in differentially oxidative tissues of notothenia rossii. Comp. Biochem. Physiol. Part B 166, 48-57. https://doi.org/10.1016/j.cbpb.2013.06.006.

Tikunov, A.P., Johnson, C.B., Lee, H., Stoskopf, M.K., Macdonald, J.M., 2010 Metabolomic investigations of American oysters using 1H-NMR spectroscopy. Mar. Drugs 8, 2578-2596. https://doi.org/10.3390/md8102578.

Tocher, D.R., Bendiksen, E.A., Campbell, P.J., Bell, G.J., 2008. The role of phospholipids in nutrition and metabolism of teleost fish. Aquaculture 280, 21-34.

Treberg, J.R., Wilson, C.E., Richards, R.C., Ewart, K.V., Driedzic, W.R., 2002. The freeze-avoidance response of smelt Osmerus mordax. J. Exp. Biol. 205 (10), 1419-1427.

Turner, J., Colwell, S.R., Marshall, G.J., Lachlan-Cope, T.A., Carleton, A.M., Jones, P.D., Lagun, V., Reid, P.A., Iagovkina, S., 2005. Antarctic climate change during the last 50 years. Int. J. Climatol. 25, 279-294. https://doi.org/10.1002/joc.1130.

Turner, J., Lu, H., White, I., King, J.C., Phillips, T., Hosking, J.S., Bracegirdle, T.J., Marshall, G.J., Mulvaney, R., Deb, P., 2016. Absence of 21st century warming on Antarctic Peninsula consistent with natural variability. Nature 535, 411-415. https://doi.org/ 10.1038 /nature18645.

Van Waarde, A., 1983. Review: aerobic and anaerobic ammonia production by fish. Comp. Biochem. Physiol. 74, 675-684.

Van Waarde, A., 1988. Biochemistry of non-protein nitrogenous compounds in fish includ ing the use of amino acids for anaerobic energy production. Comp. Biochem. Physiol. Part B 91, 207-228.

Vesala, L., Salminen, T.S., Koštál, V., Zahradníčková, H., Hoikkala, A., 2012. Myo-inositol as a main metabolite in overwintering flies: seasonal metabolomic profiles and cold stress tolerance in a northern drosophilid fly. J. Exp. Biol. 215 (16), 2891-2897. https: //doi.org/10.1242/jeb.069948.

Viant, M.R., Rosenblum, E.S., Tjeerdema, R.S., 2003. NMR-based metabolomics: a powerful approach for characterizing the effects of environmental stressors on organism health. Environ. Sci. Technol. 37, 4982-4989. https://doi.org/10.1021/es034281x.

Webb, P.W., 1971. The swimming energetics of trout. II. Oxygen consumption and swimming efficiency. J. Exp. Biol. 55, 521-540.

Windisch, H.S., Kathover, R., Portner, H.-O., Frickenhaus, S., Lucassen, M., 2011. Thermal acclimation in Antarctic fish: transcriptomic profiling of metabolic pathways. Am. J. Phys. Regul. Integr. Comp. Phys. 301, R1453-R1466. https://doi.org/10.1152/ ajpregu.00158.2011.

Windisch, H.S., Frickenhaus, S., John, U., Knust, R., Pörtner, H.O., Lucassen, M., 2014 Stress response or beneficial temperature acclimation: transcriptomic signatures in Antarctic fish (Pachycara brachycephalum). Mol. Ecol. 23 (14), 3469-3482. https:// doi.org/10.1111/mec. 12822 .

Wu, H., Southam, A.D., Hines, A., Viant, M.R., 2008. High-throughput tissue extraction protocol for NMR- and MS-based metabolomics. Anal. Biochem. 372, 204-212. https: //doi.org/10.1016/j.ab.2007.10.002

Xia, J., Wishart, D.S., 2016. Using metaboanalyst 3.0 for comprehensive metabolomics data analysis. Curr. Protoc. Bioinformatics.(14-10).

Xu, H.-D., Wang, J.-S., Li, M.-H., Liu, Y., Chen, T., Jia, A.-Q., 2015. 1H NMR based metabolomics approach to study the toxic effects of herbicide butachlor on goldfish (Carassius auratus). Aquat. Toxicol. 159, 69-80. https://doi.org/10.1016/j.aquatox. 2014.11.020.

Yancey, P.H., 2005. Organic osmolytes as compatible, metabolic and counteracting cytoprotectants in high osmolarity and other stresses. J. Exp. Biol. 208, 2819-2830. https: //doi.org/10.1242/jeb.01730.

Zhang, L., Liu, X., You, L., Zhou, D., Wu, H., Li, L., Zhao, J., Feng, J., Yu, J., 2011. Metabolic responses in gills of Manila clam Ruditapes philippinarum exposed to copper using NMR-based metabolomics. Mar. Environ. Res. 72, 33-39. https://doi.org/10. 1016/j.marenvres.2011.04.002. 
The spectra were processed and analysed with Chenomx NMR Suite 8.0 software (Chenomx Inc., 2014). Fourier-transformed spectra were multiplied with an exponential weighing function corresponding to a line-broadening between 0.5 and $1 \mathrm{~Hz}$ depending on spectrum quality. Before analysing them, all spectra were manually corrected for phase and baseline and referenced to TSP. The metabolite peaks of the processed spectra were analysed and assigned to their chemical shifts using the Chenomx database as a reference. The assigned peaks were compared and confirmed by chemical shift values in the literature (Fan, 1996; Gribbestad et al., 2005; Castejón et al., 2010). The concentration of the assigned metabolites was provided by the Chenomx software based on the concentration of the internal standard TSP. In addition to the one-dimensional ${ }^{1} \mathrm{H}-\mathrm{NMR}$ spectrometry, a two-dimensional heteronuclear single quantum coherence measurement $\left({ }^{1} \mathrm{H}^{13} \mathrm{C}\right.$ HSQC NMR) of a $N$. rossii sample was taken and the resulting 2D spectrum was used to assist in assigning signals from the ${ }^{1} \mathrm{H}-\mathrm{NMR}$ spectra (see Supplementary S1). The correlated resonances were identified using the online database Spectral Database for Organic Compounds (SDBS, $\mathrm{Na}$ tional Institute of Advanced Industrial Science and Technology, Japan) together with data from the literature (see above).

For multivariate analysis, unsupervised principle component analysis (PCA) and supervised partial least-squares discriminant analysis (PLS-DA) were applied using Metaboanalyst software (Metaboanalyst 3.0; Xia and Wishart, 2016). Multivariate analysis was conducted for each pair of groups separately (both control groups, control vs. $5{ }^{\circ} \mathrm{C}$ acclimated group for each species and both groups acclimated to the ele- vated temperature). Results are presented reporting the scores of the principle components and showing a 2D score plot of the first two principle components. An example for a PCA and a PLS-DA loadings plot is presented in the Supplementary (S2).

The main metabolite groups affected were amino acids, osmolytes and phospholipid metabolism related compounds. The largest changes are visible in the concentration of the osmolyte TMAO and the structural component myo-inositol, which both exist in high concentrations in the tissue, and of acetate (data not shown, see Supplementary material S3).

Besides the obvious role of amino acids in protein synthesis, free amino acids can also fuel the carbohydrate metabolism at higher temperatures. The degradation of branch-chain amino acids (BCAA), such as isoleucine, leucine and valine, leads to succinyl CoA, an intermediate of the tricarboxylic acid (TCA) cycle and glucogenic compounds that facilitates gluconeogenesis (Harvey and Ferrier, 2011). Those branched amino acids occur in lower concentrations in both species at warmer temperatures (data not shown, see Supplementary S3), which might be the result of a metabolic shift to carbohydrate-based metabolism, as indicated in the Antarctic eelpout to warming (Windisch et al., 2014). In the same study Windisch et al. proposed the importance of the glycine metabolism at low temperatures, since a strong temperature dependency in the expression of the glycine cleavage system was found in Antarctic eelpout. Indeed, glycine concentrations were reduced in both species acclimated to $5{ }^{\circ} \mathrm{C}$. Whether the glycine cleavage system serves at low temperatures the catabolism of excessive glycine or rather its anabolism needs still to be investigated in future studies. 